
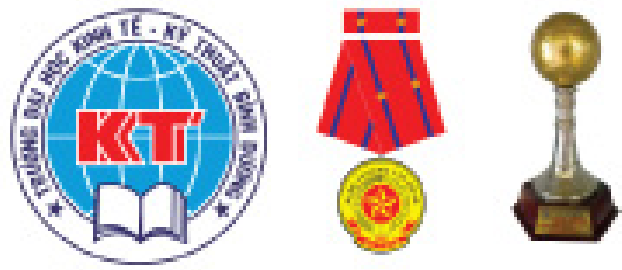

ISSN:0866 - 7802

$\frac{\text { Số } 24}{12-2018}$

3 THÁNG 1 KỲ

Tạp chí

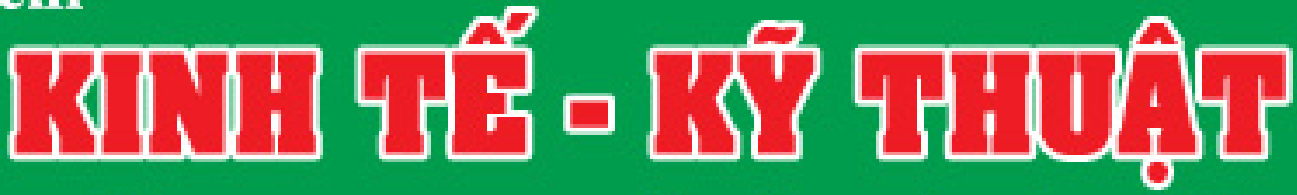

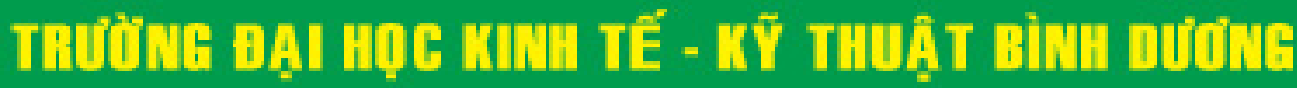

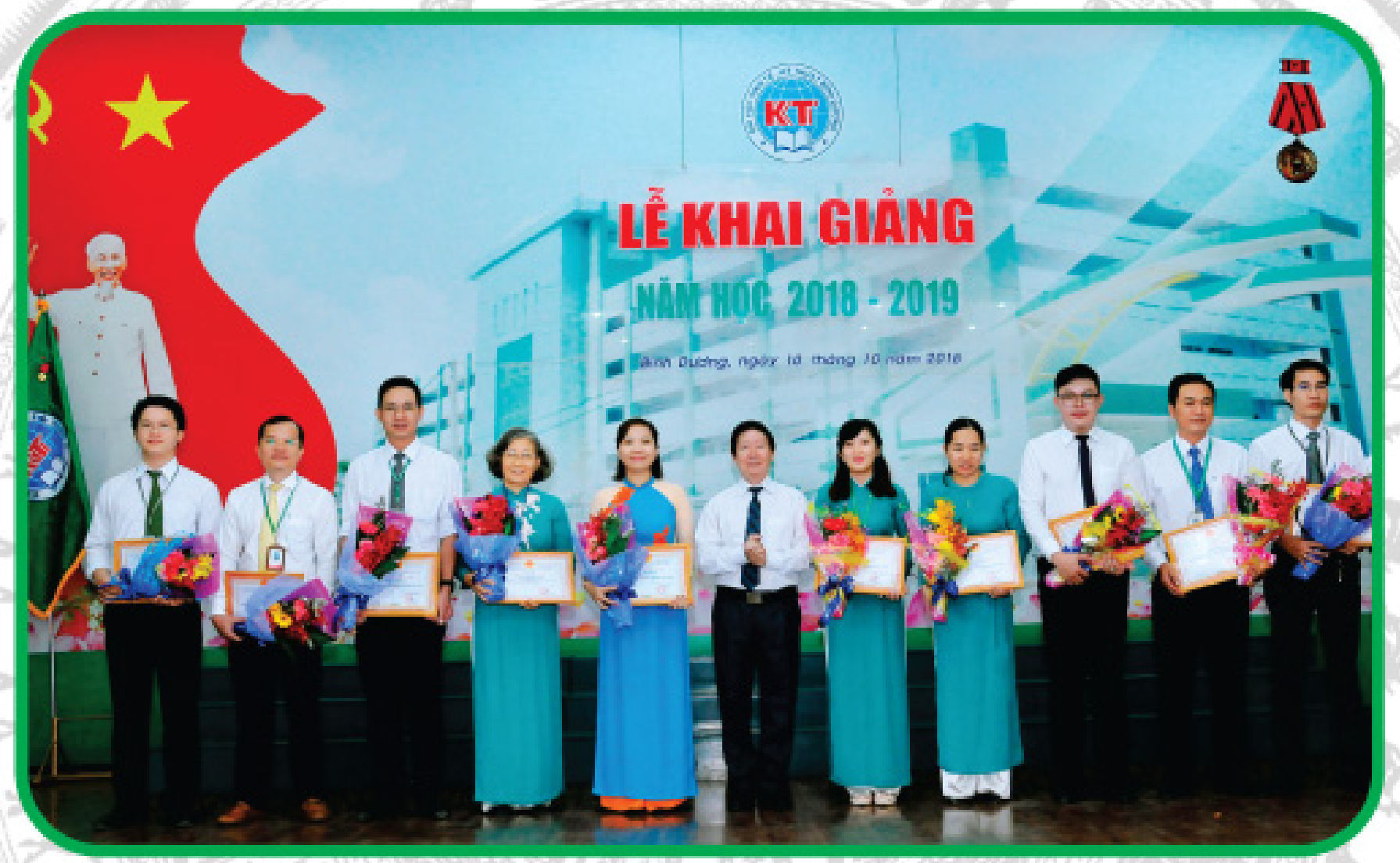



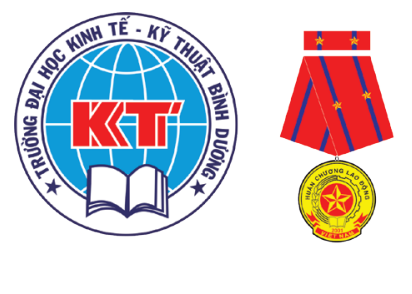

\section{KINH TẾ - KỸ THUẬT}

Tòa soạn \& trị sự:

530 Đại lộ Bình Dương, Phường Hiệp Thành, TP. Thủ Dầu Một, Tỉnh Bình Dương

Email: tapchiktktbd@gmail.com

ISSN: 0866 - 7802

\section{$\frac{\text { SỐ: (24) }}{12-2018}$}

\begin{tabular}{|c|}
\hline $\begin{array}{c}\text { Tổng Biên tập } \\
\text { PGS.TS.NB. Nguyễn Thanh } \\
\star\end{array}$ \\
\hline $\begin{array}{l}\text { Phó Tổng Biên tập } \\
\text { TS.NB. Trân Thanh Vũ }\end{array}$ \\
\hline $\begin{array}{l}\text { Hội đồng Biên tập } \\
\text { Chủ tịch: } \\
\text { TS.NB. Lê Bích Phương }\end{array}$ \\
\hline Các ủy viên: \\
\hline
\end{tabular}

GS.TS.DS. Nguyễn Văn Thanh GS.TS. Hoàng Văn Châu GS.TS. Hồ Đức Hùng GS.TS. Hoàng Thị Chỉnh PGS.TS. Nguyễn Mạnh Hùng PGS.TS. Đỗ Linh Hiệp PGS.TS. Nguyễn Quốc Tế PGS.TS. Phạm Văn Dược PGS.TS. Phương Ngọc Thạch PGS.TS. Võ Văn Nhị PGS.TS. Phước Minh Hiệp PGS.TS. Phùng Đình Mẫn PGS.TS. Phạm Minh Tiến TS. Nguyễn Hữu Thân TS. Nguyễn Tường Dũng TS. DS. Trịnh Việt Tuấn

\section{Thư ký Tòa soạn:}

ThS. Trịnh Hoàng Xuân Phúc

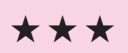

Giấy phép Hoạt động Báo chí in Số: 36/GP-BTTTT cấp ngày 05/02/2013

Số lượng in: 2.000 cuốn

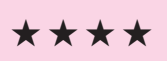

Chế bản và in tại Nhà in: Liên Tường, Quận 6, Tp.HCM 


\title{
SỰ THỎA MÃN KHÁCH HÀNG TẠI SÀN THƯƠNG MẠI ĐIỆN TỬ SENDO.VN
}

\section{TÓM TẮT}

\author{
Hà Nam Khánh Giao*, Đinh Lê Thuý Vy**
}

Nghiên cứu này có bốn mục tiêu cu thể là: (1) Xác định các yếu tố tác động đến sụ thoả mãn của khách hàng về chất lương dịch vu trục tuyến tại Sàn thuơng mại điện tử Sendo.vn, (2) Đo lường mức độ tác động của các yếu tố, (3) Kiểm định sự khác biệt về sự thoả mãn giữa các nhóm khách hàng có đặc điểm khác nhau về giới tính, độ tuổi, thu nhập, trình độ học vấn, nghề nghiệp, (4) Đề xuất một số hàm ý quản trị giúp Sàn thương mại điện tử Sendo.vn nâng cao chất lượng dịch vụ trực tuyến, bằng việc phỏng vấn trực tiếp và trực tuyến 200 khách hàng cá nhân đã từng mua sắm tại Sàn thương mại điện tử Sendo.vn trong ít nhất 6 tháng gần đây theo phương pháp chọn mẫu thuận tiện. Nghiên cứu sư dụng công cu SPSS 20 để phân tích độ tin cậy thang đo qua hệ số Cronbach's Alpha, phân tích nhân tố khám phá EFA, phân tích hồi quy tuyến tính bội.

Kết quả kiểm định mô hình chỉ ra bốn yếu tố ảnh hưởng tích cực đến sụ thoả mãn của khách hàng về chất lương dịch vu trục tuyến tại Sàn thưong mại điện tủ Sendo.vn theo thư tụ độ mạnh giảm dần: (1) Độ tin cậy, (2) Dịch vu khách hàng, (3) Thiết kế trang web và (4) Độ an toàn. Ngoài ra, kết quả cho thấy không có sụ khác biệt về sụ thoả mãn của khách hàng theo trình độ học vấn nhung lại có sụ khác biệt theo nghề nghiệp và thu nhập, giới tính, độ tuổi. Tù đó, một số hàm ý quản trị đurợc đề xuất cho cho doanh nghiệp nhằm nâng cao chất lương dịch vu mua sắm trục tuyến tại Sàn Thuơng mại điện tủ Sendo.vn.

Từ khóa: chất lựng dịch vụ mua sắm trục tuyến, sụ̣ thỏa mãn khách hàng, sàn Thuơng mại điện tủ̉ Sendo.vn.

\section{CUSTOMER SATISFACTION AT SENDO.VN E-COMMERCIAL ROOM}

\section{ABSTRACT}

This study has four specific objectives: (1) Identifying factors that affect customer satisfaction on online service quality at Sendo.vn, (2) Measurement the level of impact of the factors, (3) to test the difference in satisfaction among groups of customers with different characteristics in terms of gender, age, income, education level, occupation, (4) Proposed some governance implications for Sendo.vn. The online shopping platform enhances the quality of online services by direct and online interviews with 200 individual customers who have shopped at the floor. Electronic Sendo.vn for at least the last 6 months by convenient sampling method. The SPSS 20 tool was used to analyze the reliability of the scale through the Cronbach's Alpha coefficient, EFA discovery factor analysis, multiple linear regression analysis.

\footnotetext{
* PGS.TS. Viện Nghiên cứu Kinh tế úng dụng, trương Đại học Tài Chính-Marketing.

E-mail: khanhgiaohn@yahoo.com, Điện thoại di động: (84) 903306363

**ThS. Công ty TNHH Điện Tủ Samsung Vina. E-mail: dinhlethuyvy@gmail.com. Điện thoại di động: (84) 974761011
} 
The results of the model test indicate four factors that positively influence customer satisfaction in terms of online service quality at Sendo.vn, in order of decreasing strength: (1) (2) Customer Service, (3) Website Design and (4) Safety. In addition, the results show that there is no difference in the satisfaction of customers by educational level but there are differences by profession and income, sex, age. From there, a number of management implications are proposed for businesses to improve the quality of online shopping at Sendo.vn.

Key words: quality of online shopping service, customer satisfaction, Sendo.vn.

\section{GIÓ́I THIÊUU}

Ở Việt Nam, Internet ngày càng trở nên gắn bó và có ảnh hưởng trực tiếp đến thói quen tiêu dùng của một bộ phận lớn người Việt. Dịch vụ mua hàng trực tuyến cũng từ đó mà trở nên phổ biến và được khá nhiều người lựa chọn, đặc biệt là với những người bận rộn. Theo Báo cáo Thương mại điện tử Việt Nam 2015 của Cục Thương mại Điện tử và Công nghệ thông tin (VECITA - Bộ Công Thương) cũng chỉ ra rằng tỷ lệ người truy cập Internet tham gia mua sắm trực tuyến là $62 \%$. Ước tính giá trị mua sắm trực tuyến của mỗi cá nhân ở mức trên 1 triệu đồng/ năm, trong đó $32 \%$ người mua hàng cho biết đã chi tiêu trên 5 triệu đồng cho các giao dịch mua hàng trực tuyến. Điều này cho thấy ngành Thương mại điện tử Việt Nam được đánh giá là "mảnh đất vàng", “đầy tiềm năng” và "vô cùng màu mỡ".

Tuy nhiên, những lo ngại về sản phẩm kém chất lượng, sự yếu kém trong khâu giao nhận vận chuyển, các kênh thanh toán trực tuyến chưa chuyên nghiệp hoặc chưa bảo mật thông tin, hoặc người mua chưa có thẻ tín dụng hay các loại thẻ thanh toán, cũng những lo ngại về bảo hành, người bán không thực hiện đúng cam kết,... đã gây ra rất nhiều khó khăn trở ngại cho ngành Thương mại điện tử nói chung và Công ty Cổ phần Công nghệ Sen Đỏ nói riêng (chính là Sàn Thương mại điện tử Sendo.vn) vì chưa nhận được sự tin tưởng và thoả mãn cao trong người tiêu dùng, làm hạn chế quy mô và doanh thu chưa xứng với tiềm năng. Vì vậy, việc nghiên cứu sự thoả mãn khách hàng về chất lượng dịch vụ trực tuyến tại sàn thương mại điện tử sendo. vn là thật sự cần thiết.

Sendo.vn (Sen Đỏ) là Sàn thương mại điện tử của Tập đoàn FPT kết nối người mua và người bán trên toàn quốc. Xuất thân là một dự án Thương mại Điện tử do Công ty Cổ phần Dịch vụ trực tuyến FPT (FPT Online) phát triển, Sendo. vn ra mắt người tiêu dùng vào tháng 09/2012. Hình thức kinh doanh chính của Sendo.vn là $\mathrm{C} 2 \mathrm{C}$, thông qua các gian hàng mở tại Sendo. vn, doanh nghiệp vừa và nhỏ hoàn toàn có thể cung cấp sản phẩm, dịch vụ tốt nhất tới người tiêu dùng. Ngày 13/05/2014, Công ty Cổ phần Công nghệ Sen Đỏ được thành lập, trực thuộc Tập đoàn FPT, là đơn vị chủ quản của Sendo.vn.

Ngày 07/07/2014 là một cột mốc lớn khi Công ty Cổ phần Công nghệ Sen Đỏ mua lại 123 mua.vn, là trang thương mại điện tử hàng đầu Việt Nam của tập đoàn VNG, đánh dấu cho sự phát triển lớn mạnh của mình. Cũng trong năm đó, Sendo.vn ra mắt ứng dụng di động với nhiều cải tiến đột phá, nhằm hướng đến một trải nghiệm mua sắm tốt nhất cho người dùng trên thiết bị di động. Với mục tiêu là tạo ra một trung tâm mua sắm uy tín số 1 về giao dịch tại Việt Nam và liên tục nâng cao lòng tin của khách hàng khi mua sắm trên Sàn thương mại điện tử Sendo.vn, Công ty đã không ngừng nỗ lực phát triển và đạt được những thành tựu nhất định. Sendo.vn là sàn thương mại điện tử hàng đầu của Việt Nam, đạt chững chỉ cao nhất về bảo mật thông tin, hiện đang phục vụ hơn 80.000 shop với hơn 3 triệu sản phẩm từ 14 ngành hàng khác nhau. Vào ngày Hội mua sắm mùa thu 
05/12/2014 do Cục Thương mại điện tử tổ chức, Sendo.vn đã đạt mốc kỷ lục với hơn 30.000 giao dịch/ ngày.

\section{CƠ SỞ LÝ THUYẾT VÀ MÔ HÌNH NGHIÊN CÚU}

\subsection{Các khái niệm}

\section{Dịch vụ}

Dịch vụ là một khái niệm phổ biến trong marketing và kinh doanh. Có rất nhiều cách định nghĩa về dịch vụ, theo Zeithaml và Bitner (2000) thì “dịch vụ là những hành vi, quá trình và cách thức thực hiện một công việc nào đó nhằm tạo giá trị sử dụng cho khách hàng làm thỏa mãn nhu cầu và mong đợi của khách hàng". Dịch vụ là những hoạt động mà một bên (nhà cung cấp dịch vụ) có thể cung cấp cho khách hàng mà chủ yếu là vô hình và không chuyển giao quyền sở hữu (Kotler \& Amstrong, 2004). Dịch vụ có thể gắn liền hay không gắn liền với một sản phẩm vật chất. Do vậy, dịch vụ có những nét đặc trưng cơ bản để phân biệt với các sản phẩm hữu hình: Tính vô hình, Tính không đồng nhất, Tính không thể tách rời, Tính không thể cất trữ.

Theo Lehtinen \& Lehtinen (1982), chất lượng dịch vụ phải được đánh giá trên hai khía cạnh là quá trình cung cấp dịch vụ và kết quả của dịch vụ. Parasuraman et al (1985, 1988) định nghĩa "Chất lượng dịch vụ được xác định là khoảng cách giữa kỳ vọng của khách hàng về dịch vụ và cảm nhận của họ sau khi đã sử dụng dịch vụ đó”. Gronroos (2000) cũng đề nghị hai lĩnh vực của chất lượng dịch vụ đó là chất lượng kỹ thuật và chất lượng chức năng.

\section{Dịch vụ mua sắm trục tuyến}

Theo Kotler \& Amstrong (2004), mua sắm trực tuyến là việc mua hàng thông qua những kết nối điện tử giữa người mua và người bán - thường là trực tuyến. Mua sắm trực tuyến cho phép người mua liên hệ với các nhà cung cấp mới, cắt giảm chi phí mua, nhanh chóng xử lý đơn hàng. Đồng thời, các chuyên gia tiếp thị có thể kết nối trực tuyến với các khách hàng để chia sẻ thông tin marketing, bán sản phẩm và dịch vụ, cung cấp các dịch vụ hỗ trợ và duy trì mối quan hệ hiện hữu với khách hàng. Theo Bùi Thanh Tráng (2014), mua sắm trực tuyến là một quá trình mà khách hàng mua trực tiếp hàng hoá hoặc dịch vụ từ một người bán trong một thời gian xác thực thông qua internet, không qua dịch vụ trung gian, nó là một dạng của thương mại điện tử. Mua sắm trực tuyến mang lại lợi ích cho cả người mua và người bán về phương diện tìm kiếm khách hàng, thông tin sản phẩm, quá trình tương tác và phân phối sản phẩm.

Theo Santos (2003), chất lượng dịch vụ trực tuyến được xác định thông qua sự nhận xét, đánh giá tổng thể của khách hàng về quá trình cung cấp dịch vụ trong một thị trường ảo. Các doanh nghiệp đã có kinh nghiệm và thành công trong việc cung cấp dịch vụ trực tuyến thường bắt đầu bằng sự nhận định rằng ngoài sự hiện diện của trang web, giá cả thấp, điều quan trọng trong sự thành công hay thất bại còn bao gồm các yếu tố chất lượng dịch vụ trực tuyến. Khách hàng sử dụng dịch vụ trực tuyến mong đợi chất lượng dịch vụ được cung cấp bằng hoặc cao hơn chất lượng dịch vụ truyền thống được cung cấp.

\section{Sụ thoả mãn của khách hàng}

Có rất nhiều định nghĩa về sự thoả mãn của khách hàng: Sự thoả mãn là mức độ của trạng thái cảm giác của một người bắt nguồn từ việc so sánh kết quả thu được từ sản phẩm với những kỳ vọng của người đó (Kotler \& Amstrong, 2004). Bachelet (1995) định nghĩa sự thoả mãn của khách hàng là một phản ứng mang tính cảm xúc của khách hàng đáp lại với kinh nghiệm của họ với một sản phẩm hay dịch vụ. Theo Oliver (1997), sự thoả mãn là sự phản ứng của người tiêu dùng đối với việc được đáp ứng những mong muốn. Định nghĩa này có hàm ý rằng sự thoả mãn chính là sự thoả mãn của người tiêu dùng trong việc tiêu 
dùng sản phẩm hay dịch vụ do nó đáp ứng những mong muốn của họ, bao gồm cả mức độ đáp ứng trên mức mong muốn và dưới mức mong muốn.

Nhiều nghiên cứu về sự thoả mãn của khách hàng trong các ngành dịch vụ đều kết luận rằng chất lượng dịch vụ và sự thoả mãn là hai khái niệm được phân biệt. Theo quan điểm của Oliver (1993), chất lượng dịch vụ ảnh hưởng đến mức độ thoả mãn của khách hàng. Còn theo Cronin \& Taylor (1992), cảm nhận chất lượng dịch vụ dẫn đến sự thoả mãn của khách hàng. Spreng và Mackoy (1996) cũng chỉ ra rằng chất lượng dịch vụ là tiền đề của sự thoả mãn khách hàng, ngoài ra yếu tố giả cả cũng cần được xem xét khi nghiên cứu sự thoả mãn của khách hàng.

\section{Một số mô hình thang đo chất luọng dịch vu trục tuyến}

Việc ứng dụng thương mại điện tử trong các doanh nghiệp ngày càng gia tăng và các doanh nghiệp đã nhận thức được tầm quan trọng của việc đo lường và kiểm soát chất lượng dịch vụ trực tuyến. Theo đó, đã có nhiều nghiên cứu được thực hiện để phát triển và đề xuất các thang đo phù hợp với ngữ cảnh chất lượng dịch vụ trực tuyến.
Các mô hình nghiên cứu đa số là phát triển từ mô hình SERVQUAL, đặc biệt có mô hình E-SQ (Parasuraman, Zeithaml \& Malbotra, 2005) đã bao quát hầu hết các thành phần thang đo ở các nghiên cứu: (1) Tin cậy (Reliability), (2) Đáp ứng (Responsiveness), (3) Truy cập (Access), (4) Sự linh động (Flexibility), (5) Định hướng sử dụng dễ dàng (Ease of Navigation), (6) Hiệu quả (Efficiency, (7) Sự tin tưởng (Assurance/ Trust), (8) An toàn (Security/ Privacy), (9) Kiến thức về giá cả (Price Knowledge), (10) Giao diện trang web (Site Aesthetics), (11) Cách bố cục theo nhu cầu của khách hàng (Customization/ Persionalization). Parasuraman và các cộng sự (2005) phân tích lại các thành phần thang đo và đã tách các thành phần trên thàng 2 mô hình độc lập. Mô hình thứ nhất là mô hình E-S-Qual gồm 4 thành phần: (1) Hiệu quả (Efficiency), (2) Cam kết (Fullillment), (3) Sự sẵn sàng của hệ thống (System availability), (4) Bảo mật (Privacy). Mô hình thứ 2 là mô hình E-ReS-Qual gồm 3 thành phần: (1) Đáp ứng (Responsiveness), (2) Bồi thường (Compensation), (3) Sự liên hệ (Contact).

Ngoài ra, có một mô hình khá tổng quát về chất lượng bán lẻ qua mạng đó là mô hình chất lượng bán lẻ qua mạng EtailQ của Wolfinbarger \& Gilly (2003), gồm có 4 thành phần chính (Bảng 1).

Bảng 1: Thang đo chất lượng bán lẻ qua mạng EtailQ

\begin{tabular}{|l|l|l|}
\hline Thành phần & Biến quan sát & Phát biểu \\
\hline \multirow{5}{*}{ Độ tin cậy } & $\begin{array}{l}\text { Nhân được đúng hàng đã } \\
\text { đặt mua }\end{array}$ & $\begin{array}{l}\text { Tôi nhận được đúng loại hàng mà tôi đã đặt mua } \\
\text { từ trang web này. }\end{array}$ \\
\cline { 2 - 3 } & Giao hàng đúng hẹn & $\begin{array}{l}\text { Sản phẩm được giao đúng chất lượng giới thiệu } \\
\text { trên trang web. }\end{array}$ \\
\cline { 2 - 3 } & Giao hàng đúng chất lượng & $\begin{array}{l}\text { Sản phẩm được giao đúng chất lượng giới thiệu } \\
\text { trên trang web. }\end{array}$ \\
\hline \multirow{5}{*}{$\begin{array}{l}\text { Thiết kế } \\
\text { trang web }\end{array}$} & Cung cấp thông tin đầy đủ & Trang web cung cấp đẩy đủ thông tin. \\
\cline { 2 - 3 } & Quá trình xử lí hiệu quả & $\begin{array}{l}\text { Trang web không làm tôi mất nhìu thời gian } \\
\text { giao dịch. }\end{array}$ \\
\cline { 2 - 3 } & Tốc độ xử lý & $\begin{array}{l}\text { Rất nhanh chóng và dễ dàng hoàn thành } \\
\text { 1 giao dich qua web }\end{array}$ \\
\cline { 2 - 3 } & Cá nhân hoá & Mức độ cá nhân hoá của trang web là phù hợp \\
\cline { 2 - 3 } & Danh mục sản phẩm & Trang web có một danh mục sản phẩm tốt. \\
\hline
\end{tabular}




\begin{tabular}{|l|l|l|}
\hline \multirow{5}{*}{ Độ an toàn } & Bảo mật cá nhân & $\begin{array}{l}\text { Tôi cảm nhận thông tin cá nhân của tôi được bảo } \\
\text { mật tại trang web này. }\end{array}$ \\
\cline { 2 - 3 } & Cảm giác an toàn & $\begin{array}{l}\text { Tôi cảm thấy an toàn khi thực hiện giao dịch tại } \\
\text { trang web này. }\end{array}$ \\
\cline { 2 - 3 } & Bảo đảm an toàn & $\begin{array}{l}\text { Trang web có đầy đủ tính năng bảo đảm sự an } \\
\text { toàn và bảo mật. }\end{array}$ \\
\hline \multirow{3}{*}{$\begin{array}{l}\text { Dịch vụ } \\
\text { khách hàng }\end{array}$} & $\begin{array}{l}\text { Công ty rất thiện chí và sẵn sàng phản hồi yêu cầu } \\
\text { của khách hàng. }\end{array}$ \\
\cline { 2 - 3 } & $\begin{array}{l}\text { Mong muốn khắc phục/ sửa } \\
\text { chữa các vấn đề xảy ra. }\end{array}$ & $\begin{array}{l}\text { Khi gặp một vấn đề gì đó, trang web thể hiện sự } \\
\text { quan tâm mong muốn giải quyết vấn đề đó. }\end{array}$ \\
\cline { 2 - 3 } & Dịch vụ nhanh chóng & Các thắc mắc được giải đáp nhanh chóng. \\
\hline
\end{tabular}

(Nguồn: Wolfinbarger \& Gilly, 2003)

Sau khi tổng hợp, so sánh, có thể nhận thấy mô hình EtailQ của Wolfinbarger \& Gilly (2003) chứa đựng tất cả nội dung của mô hình E-SQ, E-S Qual và E-ReS Qual (Bảng 2).

Bảng 2: So sánh mô hình EtailQ, E-S Qual, E-ReS Qual

\begin{tabular}{|l|l|l|}
\hline Mô hình EtailQ & Mô hình E-S Qual & Mô hình E-ReS Qual \\
\hline Thiết kế trang web (Web design) & $\begin{array}{l}\text { Hiệu quả (Efficiency) } \\
\text { Sự sắn sàng của hệ thống } \\
\text { (System availability) }\end{array}$ & \\
\hline $\begin{array}{l}\text { Độ tin cậy (Reliability/ } \\
\text { Compliance with commitments) }\end{array}$ & Cam kết (Fullfillment) & Bảo mật (Privacy) \\
\hline Độ an toàn (Security/ Privacy) & $\begin{array}{l}\text { Đạ́p ứng (Responsiveness) } \\
\text { Bồi thường (Compensation) } \\
\text { Sự liên hệ (Contact) }\end{array}$ \\
\hline
\end{tabular}

\subsection{Mô hình nghiên cứu và các giả thuyết của Wolfinbarger \& Gilly (2003) (Bảng 2), đồng}

Dựa trên cơ sở tổng hợp và so sánh mô hình thời kế thừa các nghiên cứu trước, mô hình E-SQ, E-S Qual và E-ReS Qual của Parasuraman, nghiên cứu Wolfinbarger \& Gilly (2003) được Zeithaml \& Malhotra (2005) và mô hình EtailQ sử dụng để thực hiện đề tài này.

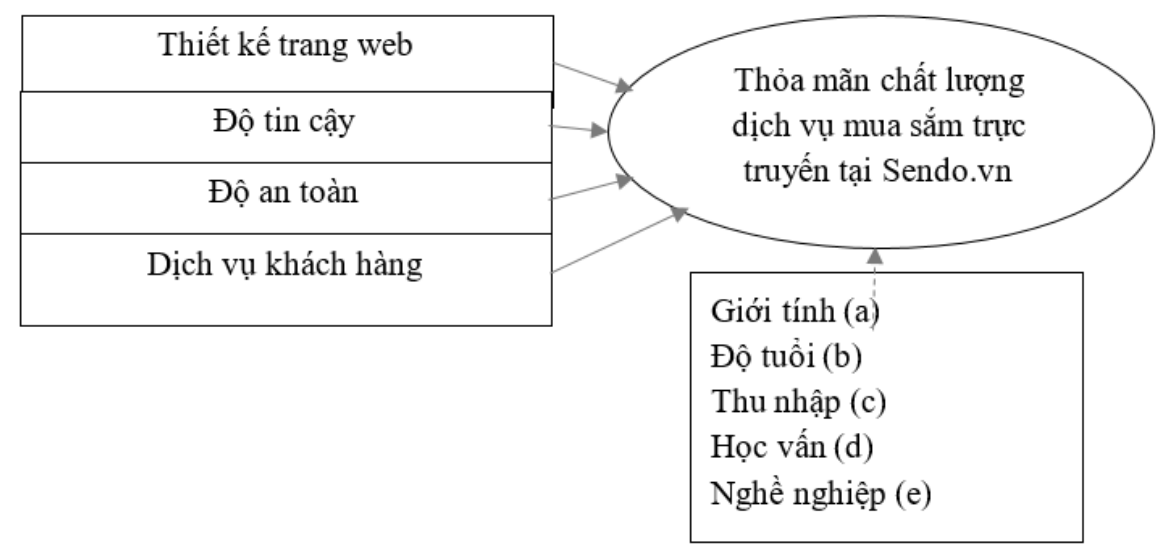

Hình 1: Mô hình nghiên cưu đề xuất 
Các giả thuyết nghiên cứu trong đề tài này gồm:

$H_{1}$ : Cảm nhận của khách hàng về thiết kế trang web tăng hay giảm thì mức độ thoả mãn của ho đối với dịch vu mua sắm trục tuyến tăng hay giảm theo.

$H_{2}$ : Cảm nhận của khách hàng về mức độ tin cầy của dịch vu mua sắm trục tuyến tại trang web tăng hay giảm thì mức độ thoả mãn của ho đối với dịch vụ mua sắm trục tuyến tăng hay giảm theo.

$H_{3}$ : Cảm nhận của khách hàng về độ an toàn của dịch vu mua sắm trục tuyến tại trang web tăng hay giảm thì múc độ thoả mãn của ho đối với dịch vu mua sắm trục tuyến tăng hay giảm theo.

$H_{4}$ : Cảm nhận của khách hàng về dịch vu khách hàng của dịch vu mua sắm trục tuyến tại trang web tăng hay giảm thì mưc độ thoả mãn của ho đối với dịch vu mua sắm trục tuyến tăng hay giảm theo.

Nhóm giả thuyết về tác động của biến nhân khẩu học lên mối quan hệ giữa chất lượng dịch vụ trực tuyến và thoả mãn khách hàng. $H_{5 a}:$ Có sụ khác biệt về thoả mãn chất lượng dịch vu mua sắm truyến theo Giới tính. $H_{5 b}$ : Có sụ khác biệt về thoả mãn chất lượng dịch vu mua sắm truyến theo Độ tuổi. $H_{5 c}$ : Có sụ khác biệt về thoả mãn chất lượng dịch vu mua sắm truyến theo Thu nhập. $H_{5 d}$ : Có sụ khác biệt về thoả mãn chất luợng dịch vu mua sắm truyến theo Trình độ hoc vấn.

$H_{5 e}$ : Có sụ khác biệt về thoả mãn chất lượng dịch vu mua sắm truyến theo Nghề nghiệp.

\section{KẾT QUẢ NGHIÊN CÚU VÀ THẢO} LUẬN

\subsection{Thống kê mô tả mẫu}

Sau khi thực hiện phỏng vấn trực tiếp và trực tuyến 250 khách hàng cá nhân đã từng mua sắm tại Sàn thương mại điện tử Sendo.vn trong ít nhất 6 tháng gần đây theo phương pháp chọn mẫu thuận tiện, còn lại 200 bảng khảo sát đáp ứng yêu cầu, được đưa vào nghiên cứu chính thức. Thống kê mô tả mẫu như trong Bảng 3 và Bảng 4.

Bảng 3: Thông tin mẫu khảo sát chính thức

\begin{tabular}{|l|l|c|c|}
\hline & \multicolumn{1}{|c|}{ Thông tin mẫu khảo sát } & Tần số & Tần suất (\%) \\
\hline \multirow{3}{*}{ 1. Giới tính } & Nam & 100 & 50,0 \\
\cline { 2 - 4 } & Nữ & 100 & 50,0 \\
\hline \multirow{3}{*}{ 3. Tuổi } & Dưới 18 tuổi & 19 & 9,5 \\
\cline { 2 - 4 } & $18-24$ & 100 & 50,0 \\
\cline { 2 - 4 } & $25-35$ & 81 & 40,5 \\
\hline \multirow{3}{*}{ 4. Học vấn } & Dưới 5 triệu & 21 & 10,5 \\
\cline { 2 - 4 } & Từ 5 - 10 triệu & 119 & 59,5 \\
\cline { 2 - 4 } & Trên 10 triệu & 60 & 30,0 \\
\hline \multirow{3}{*}{ 5. Nghề nghiệp } & Dưới Đại học & 42 & 21,0 \\
\cline { 2 - 4 } & Từ Đại học trở lên & 158 & 79,0 \\
\hline & Học sinh, sinh viên & 19 & 9,5 \\
\cline { 2 - 4 } & Nhân viên & 120 & 60,0 \\
\cline { 2 - 4 } & Quản lý & 61 & 30,5 \\
\hline
\end{tabular}

(Nguồn: Xủ lý tù SPSS) 
Bảng 4: Thống kê thói quen mua sắm

\begin{tabular}{|c|c|c|c|}
\hline & Thống kê thói quen mua sắm & Tần số & Tần suất $(\%)$ \\
\hline \multirow{4}{*}{ 1. Mức độ mua hàng } & 1 - 2 lần một tháng & 78 & 39,0 \\
\hline & 3 - 4 lần một tháng & 44 & 22,0 \\
\hline & Hơn 4 lần một tháng & 32 & 16,0 \\
\hline & Hiếm khi mua trực tuyến & 46 & 23,0 \\
\hline \multirow{5}{*}{ 2. Mặt hàng mua sắm } & Thời trang nam/ nữ, Mẹ và bé & 100 & 50,0 \\
\hline & Đồ công nghệ, điện máy & 26 & 23,0 \\
\hline & Đồ gia dụng & 22 & 11,0 \\
\hline & Thực phẩm & 17 & 8,5 \\
\hline & Khác & 15 & 7,5 \\
\hline \multirow{6}{*}{$\begin{array}{l}\text { 3. Hình thức mua sắm } \\
\text { trực tuyến }\end{array}$} & Website bán hàng trực tuyến & 43 & 21,5 \\
\hline & Sàn giao dịch điện tử & 26 & 13,0 \\
\hline & Website mua hàng theo nhóm & 33 & 16,5 \\
\hline & Các diễn đàn, mạng xã hội & 47 & 23,5 \\
\hline & $\begin{array}{l}\text { Các ứng dụng mua hàng trực tuyến cài } \\
\text { đặt trên mobile }\end{array}$ & 25 & 12,5 \\
\hline & Mục rao vặt tại các website tin tức & 26 & 13,0 \\
\hline
\end{tabular}

(Nguồn: Xư lý tù' SPSS)

\section{2. Đánh giá độ tin cậy thang đo bằng Cronbach's Alpha}

Sau khi phân tích Cronbach's Alpha, các thang đo đều đạt tiêu chí (hệ số Cronbach's Alpha 0,6 và hệ số tương quan biến - tổng hiệu chỉnh 0,3 ) (Bảng 5). Do đó, được sử dụng cho phân tích EFA tiếp theo.

Bảng 5: Kết quả tính toán độ tin cậy thang đo

\begin{tabular}{|c|c|c|c|c|c|}
\hline STT & Thang đo & $\begin{array}{c}\text { Ký } \\
\text { hiệu }\end{array}$ & $\begin{array}{c}\text { Số biến } \\
\text { quan sát }\end{array}$ & $\begin{array}{c}\text { Cronbach's } \\
\text { Alpha }\end{array}$ & $\begin{array}{c}\text { Tương quan biến }- \\
\text { tổng nhỏ nhất }\end{array}$ \\
\hline 01 & Thiết kế trang web & TK & 6 & 0.798 & .461 \\
\hline 02 & Độ tin cậy & TC & 5 & 0.873 & .511 \\
\hline 03 & Độ an toàn & AT & 5 & 0.893 & .682 \\
\hline 04 & Dịch vụ khách hàng & KH & 4 & 0.770 & .643 \\
\hline 05 & Sự thỏa mãn & STM & 4 & 0.879 & .704 \\
\hline
\end{tabular}

\subsection{Phân tích nhân tố khám phá EFA}

(Nguồn: Xư lý tù̀ SPSS)

Phân tích EFA nhóm biến độc lập cho kết quả hệ số $\mathrm{KMO}=0,766>0,5$ với mức ý nghĩa Sig $=$ $0,000<0,05$, cho thấy các biến quan sát thuộc cùng một nhân tố có tương quan chặt chẽ với nhau. Đồng thời tổng phương sai trích là $65,300 \%>50 \%$ cho thấy 4 nhân tố này giải thích $65,300 \%$ sự biến thiên của tập dữ liệu và giá trị Eigenvalue $=2,532>1$ đủ tiêu chuẩn phân tích nhân tố. 
Bảng 6: Kết quả phân tích EFA các nhân tố chất lượng dịch vu

\begin{tabular}{|c|c|c|c|c|}
\hline & & Hệs & & \\
\hline & 1 & 2 & 3 & 4 \\
\hline $\mathrm{AT}_{3}$ & 0,922 & & & \\
\hline $\mathrm{AT}_{4}$ & 0,906 & & & \\
\hline $\mathrm{AT}_{2}$ & 0,804 & & & \\
\hline $\mathrm{AT}_{1}$ & 0,799 & & & \\
\hline $\mathrm{AT}_{5}$ & 0,795 & & & \\
\hline $\mathrm{TC}_{5}$ & & 0,889 & & \\
\hline $\mathrm{TC}_{3}$ & & 0,849 & & \\
\hline $\mathrm{TC}_{2}$ & & 0,824 & & \\
\hline $\mathrm{TC}_{1}$ & & 0,817 & & \\
\hline $\mathrm{TC}_{4}$ & & 0,644 & & \\
\hline $\mathrm{TK}_{3}$ & & & 0,791 & \\
\hline $\mathrm{TK}_{1}$ & & & 0,709 & \\
\hline $\mathrm{TK}_{2}$ & & & 0,704 & \\
\hline $\mathrm{TK}_{6}$ & & & 0,696 & \\
\hline $\mathrm{TK}_{4}$ & & & 0,693 & \\
\hline $\mathrm{TK}_{5}$ & & & 0,612 & \\
\hline $\mathrm{KH}_{1}$ & & & & 0,933 \\
\hline $\mathrm{KH}_{4}$ & & & & 0,912 \\
\hline $\mathrm{KH}_{3}$ & & & & 0,810 \\
\hline $\mathrm{KH}_{2}$ & & & & 0,766 \\
\hline
\end{tabular}

(Nguồn: Xủ lý tù SPSS)

Phân tích EFA cho nhóm biến phụ thuộc cho thấy kiểm định KMO và Bartlett's trong phân tích nhân tố có kết quả sig $=0,000$ và hệ số $\mathrm{KMO}=0,801>0,5$; giá trị Eigenvalue là $2,942>1$. Do vậy các các thang đo rút ra được chấp nhận. Tất cả 4 biến quan sát đều có hệ số tải nhân tố (factor loading) lớn hơn 0,5 . Do đó thang đo đạt yêu cầu về giá trị hội tụ và độ tin cậy.

Bảng 7: Kết quả EFA của thang đo sụ thỏa mãn chất lượng dịch vụ

\begin{tabular}{|l|c|}
\hline \multirow{2}{*}{} & Hệ số tải nhân tố \\
\cline { 2 - 2 } & 1 \\
\hline $\mathrm{STM}_{4}$ & 0,897 \\
\hline $\mathrm{STM}_{3}$ & 0,861 \\
\hline $\mathrm{STM}_{2}$ & 0,837 \\
\hline $\mathrm{STM}_{1}$ & 0,834 \\
\hline
\end{tabular}

(Nguồn: Xủ lý tù SPSS) 


\subsection{Phân tích tương quan}

Kiểm tra hệ số tương quan r, cho kết quả ở bảng 8 với mức ý nghĩa 0,01 (độ tin cậy $99 \%$ ) và 0,05 (độ Tin cậy 95\%) tất cả bốn yếu tố thuộc thang đo biến độc lập đều có mối tương quan tích cực đến chất lượng dịch vụ nên có thể đưa vào thực hiện hồi quy.

Bảng 8: Kết quả phân tích tương quan Pearson

\begin{tabular}{|l|l|c|c|c|c|c|}
\hline \multicolumn{2}{|l|}{} & TK & TC & AT & KH & STM \\
\hline \multirow{2}{*}{ TK } & Pearson Correlation & 1 & $-0,120$ & 0,069 & $-0,165^{*}$ & $0,342^{* *}$ \\
\cline { 2 - 7 } & Sig. (2-tailed) & & 0,091 & 0,330 & 0,020 & 0,000 \\
\hline \multirow{2}{*}{ TC } & Pearson Correlation & $-0,120$ & 1 & $-0,069$ & $0,188^{* *}$ & $0,558^{* *}$ \\
\cline { 2 - 7 } & Sig. (2-tailed) & 0,091 & & 0,335 & 0,008 & 0,000 \\
\hline \multirow{2}{*}{ AT } & Pearson Correlation & 0,069 & $-0,069$ & 1 & 0,052 & $0,166^{*}$ \\
\cline { 2 - 7 } & Sig. (2-tailed) & 0,330 & 0,335 & & 0,465 & 0,019 \\
\hline \multirow{2}{*}{ KH } & Pearson Correlation & $-0,165^{*}$ & $0,188^{* *}$ & 0,052 & 1 & $0,366^{* *}$ \\
\cline { 2 - 7 } & Sig. (2-tailed) & 0,020 & 0,008 & 0,465 & & 0,000 \\
\hline \multirow{2}{*}{ STM } & Pearson Correlation & $0,342^{* *}$ & $0,558^{* *}$ & $0,166^{*}$ & $0,366^{* *}$ & 1 \\
\cline { 2 - 7 } & Sig. (2-tailed) & 0,000 & 0,000 & 0,019 & 0,000 & \\
\hline
\end{tabular}

(Nguồn: Xư lý tù SPSS)

\subsection{Phân tích hồi quy}

Bảng 9: Kết quả phân tích hệ số hồi quy.

\begin{tabular}{|c|c|c|c|c|c|c|c|c|}
\hline \multirow{2}{*}{\multicolumn{2}{|c|}{ Mô hình }} & \multicolumn{2}{|c|}{$\begin{array}{l}\text { Hệ số chưa } \\
\text { chuẩn hóa }\end{array}$} & \multirow{2}{*}{ 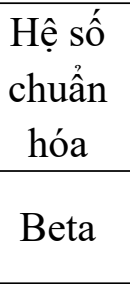 } & \multirow{2}{*}{ Giá trị $\mathrm{t}$} & \multirow{2}{*}{$\begin{array}{l}\text { Mức ý } \\
\text { nghĩa } \\
\text { Sig. }\end{array}$} & \multicolumn{2}{|c|}{ Thống kê đa cộng tuyến } \\
\hline & & $\mathrm{B}$ & $\begin{array}{l}\text { Sai số } \\
\text { chuẩn }\end{array}$ & & & & $\begin{array}{l}\text { Độ chấp } \\
\text { nhận biến }\end{array}$ & $\begin{array}{l}\text { Hệ số phóng đại } \\
\text { phương sai VIF }\end{array}$ \\
\hline \multirow{5}{*}{1} & Hằng số & $-0,231$ & 0,332 & & $-0,696$ & 0,487 & & \\
\hline & TK & 0,259 & 0,026 & 0,453 & 9,957 & 0,000 & 0,960 & 1,042 \\
\hline & $\mathrm{TC}$ & 0,297 & 0,024 & 0,561 & 12,291 & 0,000 & 0,951 & 1,051 \\
\hline & AT & 0,246 & 0,071 & 0,156 & 3,477 & 0,001 & 0,986 & 1,014 \\
\hline & $\mathrm{KH}$ & 0,280 & 0,039 & 0,327 & 7,116 & 0,000 & 0,939 & 1,065 \\
\hline \multicolumn{9}{|c|}{$\mathrm{R}^{2}$ hiệu chỉnh: 0,605} \\
\hline \multicolumn{9}{|c|}{ Thống kê Durbin-Watson: 2,076 } \\
\hline \multicolumn{9}{|c|}{ Thống kê F (ANOVA): 77,337 } \\
\hline \multicolumn{9}{|c|}{ Mức ý nghĩa (Sig. của ANOVA): 0,000} \\
\hline
\end{tabular}


Bảng 9 cho thấy $\mathrm{R}^{2}$ hiệu chỉnh là 0,605 , nghĩa là $60,5 \%$ sự biến thiên của STM (được giải thích bởi sự biến thiên của 4 biến độc lập TK, TC, AT, KH. Ngoài ra kiểm định Durbin - Watson $\mathrm{d}=2,076(1<\mathrm{d}<3)$ cho thấy mô hình không có tương quan giữa các phần dư. Giá trị sig. của $F(=77,337)$ có mức ý nghĩa sig. rất nhỏ $($ Sig. $=0,000<0,05)$, nghĩa là mô hình hồi quy tuyến tính đưa ra là phù hợp với dữ liệu thu thập được. Phương trình hồi quy chưa chuẩn hóa được thể hiện như sau: $\boldsymbol{S T M}$ $=-0,231+0,259 * T K+0,297 * T C+0,246 * A T$ $+0,280 * K \boldsymbol{H}$. Bên cạnh đó, $\beta_{2>} \beta_{4>} \beta_{1>} \beta_{3}$ do đó các yếu tố tác động đến sự thỏa mãn chung về chất lượng dịch vụ lần lượt mạnh nhất là $\mathrm{TC}>$ $\mathrm{KH}>\mathrm{TK}>\mathrm{AT}$.

\subsection{Kiểm định các giả định hồi quy}

Kiểm tra phần dư cho thấy phân phối phần dư xấp xỉ chuẩn với trung bình Mean $=0$ và độ lệch chuẩn $\mathrm{Std}$. Deviation $=0,990$ (xấp xỉ bằng 1 ) do đó có thể kết luận rằng giả thiết phân phối chuẩn không bị vi phạm khi sử dụng phương pháp hồi quy bội. Mặt khác, bằng hình ảnh trực quan ta thấy phần dư của mô hình có dạng đồ thị hình chuông úp xuống khá cân đối, nên có thể kết luận phần dư của mô hình có phân phối chuẩn.

Ngoài ra, theo biểu đồ P-P plots các điểm quan sát không phân tán quá xa đường thẳng kỳ vọng nên có thể kết luận giả thuyết về phân phối chuẩn của phần dư không bị vi phạm. Theo biểu đồ Scatterplot, các sai số hồi quy phân bố tương đối đều ở cả hai phía của đường trung bình (trung bình của các sai số bằng 0 ) và không theo một quy luật rõ ràng nào. Điều đó cho thấy giả thiết sai số của mô hình hồi quy không đổi là phù hợp.

\subsection{Kiểm định sự khác biệt}

Mục đích của việc phân tích này là tìm ra sự khác biệt về đánh giá chất lượng dịch vụ theo các yếu tố về đặc điểm của người tham gia khảo sát như giới tính, độ tuổi, trình độ, thu nhập, nghề nghiệp. Kỹ thuật phân tích phương sai
ANOVA và Kiểm định trung bình mẫu độc lập T-Test được sử dụng.

Kết quả cho có sự khác biệt về thoả mãn chất lượng dịch vụ mua sắm trực truyến theo giới tính, nữ thỏa mãn chất lượng dịch vụ tại Sendo.vn hơn nam. Kết quả cũng cho thấy có sự khác biệt về thoả mãn chất lượng dịch vụ mua sắm truyến theo độ tuổi. Cụ thể, ở độ tuổi 18-24 sự thỏa mãn chất lượng dịch vụ là cao nhất, tiếp theo là nhóm 25-35 tuổi và nhóm dưới 18 tuổi.Bên cạnh đó, có sự khác biệt về thoả mãn chất lượng dịch vụ mua sắm trực truyến theo thu nhập. Cụ thể, mức lương 5-10 triệu thì sự thỏa mãn chất lượng dịch vụ ở mức cao nhất, tiếp theo là thu nhập ở mức dưới 5 triệu có sự thỏa mãn chất lượng dịch vụ đứng thứ 2 và cuối cùng là thu nhập trên 10 triệu có sự thỏa mãn chất lượng dịch vụ thấp nhất. Kết quả cũng cho thấy không có sự khác biệt về thoả mãn chất lượng dịch vụ mua sắm truyến theo trình độ học vấn. Ngoài ra, có sự khác biệt về thoả mãn chất lượng dịch vụ mua sắm trực tuyến theo Nghề nghiệp. Cụ thể, nhóm nhân viên có sự thỏa mãn chất lượng dịch vụ cao nhất tiếp theo là đến 2 nhóm Quản lý và học sinh, sinh viên có sự thỏa mãn chất lượng dịch vụ gần bằng nhau.

\subsection{Kiểm định các giả thuyết của mô hình}

Kết quả kiểm định các giả thuyết từ phân tích tương quan, phân tích hồi quy, kiểm định T-test và phân tích phương sai ANOVA cho thấy mối quan hệ giữa các biến độc lập sự thỏa mãn về chất lượng dịch vụ với biến phụ thuộc và các biến về đặc điểm nhân khẩu học đều có ý nghĩa ở độ tin cậy là 95\%. 
Bảng 11: Kết quả kiểm định các giả thuyết

\begin{tabular}{|c|c|c|c|}
\hline \multicolumn{2}{|r|}{ Nhóm giả thuyết về tác động của biến chất lượng dịch vụ } & Hệ số hồi quy & Kết quả \\
\hline $\mathrm{H}_{1}$ & $\begin{array}{l}\text { Cảm nhận của khách hàng về thiết kế trang web tăng hay giảm } \\
\text { thì mức độ thoả mãn của họ đối với dịch vụ mua sắm trực } \\
\text { tuyến tăng hay giảm theo. }\end{array}$ & $\begin{array}{l}0,259 \\
(>0)\end{array}$ & Chấp nhận \\
\hline $\mathrm{H}_{2}$ & $\begin{array}{l}\text { Cảm nhận của khách hàng về mức độ tin cậy của dịch vụ mua } \\
\text { sắm trực tuyến tại trang web tăng hay giảm thì mức độ thoả mãn } \\
\text { của họ đối với dịch vụ mua sắm trực tuyến tăng hay giảm theo. }\end{array}$ & $\begin{array}{l}0,297 \\
(>0)\end{array}$ & Chấp nhận \\
\hline $\mathrm{H}_{3}$ & $\begin{array}{l}\text { Cảm nhận của khách hàng về độ an toàn của dịch vụ mua sắm } \\
\text { trực tuyến tại trang web tăng hay giảm thì mức độ thoả mãn của } \\
\text { họ đối với dịch vụ mua sắm trực tuyến tăng hay giảm theo. }\end{array}$ & $\begin{array}{l}0,246 \\
(>0)\end{array}$ & Chấp nhận \\
\hline $\mathrm{H}_{4}$ & $\begin{array}{l}\text { Cảm nhận của khách hàng về dịch vụ khách hàng của dịch vụ mua } \\
\text { sắm trực tuyến tại trang web tăng hay giảm thì mức độ thoả mãn } \\
\text { của họ đối với dịch vụ mua sắm trực tuyến tăng hay giảm theo }\end{array}$ & $\begin{array}{l}0,280 \\
(>0)\end{array}$ & Chấp nhận \\
\hline \multicolumn{2}{|r|}{ Nhóm giả thuyết về tác động của biến nhân khẩu học } & Sig & Kết quả \\
\hline $\mathrm{H}_{5 \mathrm{a}}$ & $\begin{array}{l}\text { Có sự khác biệt về thoả mãn chất lượng dịch vụ mua sắm trực } \\
\text { truyến theo Giới tính }\end{array}$ & $\begin{array}{l}0,000 \\
<0,05\end{array}$ & Chấp nhận \\
\hline $\mathrm{H}_{5 b}$ & $\begin{array}{l}\text { Có sự khác biệt về thoả mãn chất lượng dịch vụ mua sắm trực } \\
\text { truyến theo Độ tuổi }\end{array}$ & $\begin{array}{l}0,000 \\
<0,05\end{array}$ & Chấp nhận \\
\hline $\mathrm{H}_{5 \mathrm{c}}$ & $\begin{array}{l}\text { Có sự khác biệt về thoả mãn chất lượng dịch vụ mua sắm trực } \\
\text { truyến theo Thu nhập }\end{array}$ & $\begin{array}{l}0,000 \\
<0,05\end{array}$ & Chấp nhận \\
\hline $\mathrm{H}_{5 \mathrm{~d}}$ & $\begin{array}{l}\text { Có sự khác biệt về thoả mãn chất lượng dịch vụ mua sắm trực } \\
\text { truyến theo Trình độ học vấn }\end{array}$ & $\begin{array}{l}0,062 \\
>0,05\end{array}$ & Bác bỏ \\
\hline $\mathrm{H}_{5 \mathrm{e}}$ & $\begin{array}{l}\text { Có sự khác biệt về thoả mãn chất lượng dịch vụ mua sắm trực } \\
\text { truyến theo Nghề nghiệp }\end{array}$ & $\begin{array}{l}0,000 \\
<0,05\end{array}$ & Chấp nhận \\
\hline
\end{tabular}

(Nguồn: Xủ lý tù̀ SPSS)

\section{KẾT LUẬN VÀ HÀM Ý QUẢN TRI}

\subsection{Kết luận}

Nghiên cứu này được thực hiện với mục tiêu xác định và đo lường mức độ tác động của các yếu tố chất lượng dịch vụ trực tuyến đến sự thoả mãn của khách hàng tại Sàn thương mại điện tử Sendo.vn. Nghiên cứu được tiến hành thông qua phương pháp nghiên cứu hỗn hợp định tính và định lượng với số mẫu hợp lệ thu được là 200.

Theo kết quả nghiên cứu, có 04 nhân tố có ảnh hưởng đến sự thoả mãn của khách hang, theo thứ tự giảm dần: Độ tin cậy, Dịch vụ khách hàng, Thiết kế trang web và Độ an toàn. Kết quả cũng cho thấy tất cả các biến điều tiết Nhân khẩu học gồm Giới tính, Độ tuổi, Thu nhập và Nghề nghiệp đều có sự khác biệt đối với Sự thoả mãn của khách hàng mua sắm tại Sendo.vn, ngoại trừ biến Trình độ học vấn.

\subsection{Hàm ý quản trị}

\section{Về nhân tố Độ tin cậy}

Các biến quan sát đều được đánh giá khá tốt, trong đó có 3 biến $\mathrm{TC}_{2}, \mathrm{TC}_{3}$ và $\mathrm{TC}_{5}$ trên mức trung hoà nhưng chưa đến mức đồng ý.

$\mathrm{TC}_{5}$ (Sàn TMĐT Sendo.vn luôn giũ đúng cam kết về các chuơng trình khuyến mại trục tuyến) được đánh giá thấp nhất, chứng tỏ khách hàng đang có thái độ rất tiêu cực với các chương trình khuyến mãi trực tuyến tại Sendo.vn. Điều này cũng khiến cho các nhà quản trị của Sendo. 
vn phải đau đầu khi mà ngày càng có nhiều người bán thổi phồng thông tin giá gốc của sản phẩm, tạo khuyến mãi “ảo”, sản phẩm hết hàng mà không hạ thông tin, chất lượng không đúng như mô tả... khiến cho khách hàng giảm niềm tin vào chương trình cũng như doanh nghiệp. Tất nhiên, Sendo.vn vẫn đang cố gắng tìm cách giải quyết triệt để yếu tố này để tạo dựng niềm tin nơi khách hàng.

$\mathrm{TC}_{3}$ (Sàn TMĐT Sendo.vn có chính sách hoàn trả rõ ràng) là nhân tố được đánh giá thấp tiếp theo, cho thấy việc giao nhận cũng như đổi trả sản phẩm chưa đạt được yêu cầu của khách hàng. Sendo.vn có đặt ra các chính sách hoàn trả cho các shop tham gia bán, tuy nhiên việc thực hiện trực tiếp lại xảy ra giữa người bán và người mua mà không thông qua Sendo.vn, chính vì vậy không thể tránh khỏi những trường hợp xấu do shop không hợp tác. Ngoài ra, đến nay một số khách hàng trung thành vẫn chưa thể nhận biết được Sendo.vn là một sàn TMĐT, họ nghĩ Sendo. vn là shop. Vậy nên, mọi hoạt động sai lầm từ người bán đều bị quy kết về cho Sendo.vn.

$\mathrm{TC}_{2}$ (Tôi nhận được đúng hàng ngay từ lần đầu tiên (số lượng, chủng loại,...)) là nhân tố tiếp theo mà khách hàng kém đồng ý. Sendo.vn cần phải làm việc sâu sát hơn với tập người bán để từng bước cải thiện yếu tố này, làm cho khách hàng thoả mãn hơn với chất lượng dịch vụ trực tuyến của mình.

Một số đề xuất nhằm nâng cao độ tin cậy của khách hàng, từ đó làm tăng mức độ thoả mãn của khách hàng khi mua sắm tại Sendo. vn: Các cam kết của Sendo.vn đối với dịch vụ trực tuyến và các chương trình khuyến mãi phải luôn thực hiện đúng, công khai rõ ràng về thời gian thực hiện, nội dung và kết quả. Các chương trình khuyến mãi sẽ được một đội xét duyệt chặt chẽ thông tin, ràng buộc điều kiện để tránh tình trạng người bán đẩy giá gốc lên rồi treo giảm giá $50-70 \%$. Ngoài ra, Sendo.vn có thể thực hiện cơ chế người mua phản ánh người bán, sau khi xác nhận là đúng sự thật, người bán sẽ bị hạ điểm uy tín, ảnh hưởng đến thứ tự xếp hạng và khả năng xuất hiện các sản phẩm trên hệ thống. Sendo.vn cần đặt ra chế tài nghiêm ngặt cho những người bán nào không thực hiện đúng các quy định chính sách đã đặt ra. Nếu có khách hàng báo xấu, vi pham, người bán sẽ bị hạ sản phẩm ngay lập tức. Đồng thời, Sendo. vn cũng có những chương trình bảo vệ quyền lợi cho khách hàng, khuyến khích lập tức gửi khiếu nại trong vòng 48h kể từ khi nhận hàng. Sau khi thu thập, xem xét và lắng nghe mọi bằng chứng liên quan được cung cấp, khách hàng có thể được hoàn tiền $100 \%$ giá trị sản phẩm chẳng hạn trong trường hợp xác định sai phạm hoàn toàn thuộc về người bán hay nhân viên vận chuyển. Hệ thống trang web cần phải được thiết kế rõ ràng hơn, đặc biệt là phần chọn chủng loại sản phẩm để luôn thực hiện chính xác các yêu cầu và câu lệnh của khách hàng. Ngoài ra, tránh trường hợp sản phẩm đã hết hàng, người bán gửi sản phẩm tương tự cho người mua mà không thông qua ý kiến, Sendo.vn khuyến khích các khách hàng kiểm tra sản phẩm ngay từ lúc nhận hàng. Nếu không đúng sản phẩm mà khách hàng đã chọn, họ có quyền không lấy sản phẩm đó và người bán sẽ phải chịu phí chuyển hồi.

\section{Về nhân tố Dịch vụ khách hàng}

Nhìn chung, tất cả các biến đều trong khoảng xấp xỉ 4.2 đến 4.4 , riêng có biến $\mathrm{KH}_{2}$ (Nhân viên của Sàn TMĐT Sendo.vn tư vấn kĩ càng, hướng dẫn và hỗ trợ tôi trong những lúc tôi gặp sự cố khi giao dịch) được đánh giá thấp nhất. Do đó, cần thiết phải duy trì và cải thiện hơn nữa yếu tố Dịch vụ khách hàng để tăng cường sự thoả mãn của khách hàng khi mua sắm trực tuyến tại Sendo.vn. Một số đề xuất đối với nhân tố Dịch vụ khách hàng như sau:

Tốc độ xử lý phản hồi nhanh chóng, phản ứng ngay lập tức với những thắc mắc, khiếu nại của khách hàng và liên tục chăm sóc khách hàng là một trong những chìa khoá đem lại sự hài lòng và niềm tin cho khách hàng. Do đó, Sendo. vn cần cải tiến quy trình phản hồi thông tin và 
xử lý khiếu nại, đảm bảo các bước tiếp nhận hồ sơ, xử lý thắc mắc khiếu nại đến thông báo kết quả cho khách hàng phải nằm trong khung thời gian tối đa cho phép, đồng thời đảm bảo quy trình này được tuân thủ nghiêm túc. Khách hàng phải luôn luôn được cập nhật xem thắc mắc của mình đang được giải quyết đến đâu và khi nào có kết quả xử lý.

Ngoài các thông tin được cung cấp trên trang web hiện tại, nên trang bị thêm các robot chat và hiển thị tại vị trí bắt mắt trên trang web để phục vụ khách hàng tốt hơn, đảm bảo khách hàng luôn kết nối được với bộ phận chăm sóc khách hàng của Sendo.vn khi họ cần. Bổ sung mục "Gọi Bộ phận Chăm sóc khách hàng" trên ứng dụng để khách hàng có thể sử dụng gọi điện thoại bất cứ lúc nào.

Cần thường xuyền tổ chức các lớp đào tạo nhân viên về dịch vụ khách hàng, kỹ năng đàm phán, kỹ năng giao tiếp, kỹ năng giải quyết vấn đề,..., thường xuyên cập nhật kiến thức nghiệp vụ cho nhân viên để tư vấn và hướng dẫn cho khách hàng tốt hơn, hạn chế những lỗi nghiệp vụ làm phiền lòng khách hàng. Tăng cường nhân lực chăm sóc khách hàng thông qua số hotline, email đặc biệt là những khi có sự cố giao dịch xảy ra.

\section{Về nhân tố Thiết kế trang web}

Có thể thấy độ chênh lệch đánh giá của khách hàng giữa các biến quan sát không cao. Tuy thành phần này không tác động mạnh đến sự thoả mãn của khách hàng khi mua sắm trực tuyến tại Sendo.vn. Thiết kế trang web tạo nên ấn tượng đầu tiên trong lòng khách hàng khi vừa truy cập vào. Do đó, Sendo.vn vẫn phải chú trọng đến yếu tố này để gia tăng sự thoả mãn của khách hàng với các chất lượng dịch vụ trực tuyến tại Sendo.vn.

Sendo.vn cần thẩm định lại tính thẩm mỹ và các tính năng, tiện ích của trang web. Tham khảo thiết kế trang web của các đối thử khác để tiếp thu những ưu điểm. Hơn nữa, nên định kỳ thực hiện $\mathrm{A} / \mathrm{B}$ Testing để nắm bắt được thị hiếu của người dung, nâng cấp giao diện để bắt mắt người xem và giúp khách hàng cảm thấy hứng thú, không nhàm chán trong quá trình thực hiện giao dịch. Tuy nhiên, vẫn phải đảm bảo trang web được thiết kế đơn giản, gọn nhẹ, không quá rắc rối, cầu kì.

Cần đơn giản hoá các thao tác cho khách hàng khi thực hiện giao dịch, giảm số lần bấm chuột đến mức ít nhất có thể để hoàn tất một giao dịch. Trang web cần có những bước làm mẫu minh hoạ hoặc chỉ dẫn rõ ràng để khách hàng dễ hiểu các thủ tục và thực hiện được một cách dễ dàng. Cấu trúc trang web nên rõ ràng, dễ dàng tìm kiếm và thao tác, không làm cho khách tốn quá nhiều thời gian để tìm kiếm một thông tin nào đó hay tìm hiểu thủ tục, cách thức giao dịch qua trang web.

Cần nâng cấp hệ thống máy chủ, cáp quang và thường xuyên kiểm tra, bảo trì để đảm bảo đường truyền tốt, tối ưu hoá tốc độ xử lý truy cập trang web. Đảm bảo cung cấp thông tin chính xác, đúng, đầy đủ, kịp thời và thường xuyên để khách hàng luôn có được thông tin cập nhật mới nhất và tìm được thông tin mà họ cần. Quy định rõ ràng cho người bán về việc đăng thông tin, hình ảnh sản phẩm như thế nào là hợp lệ và cần có một bộ phận kiểm duyệt trước khi lên trang.

\section{Về nhân tố Độ an toàn}

Nhận xét đánh giá của khách hàng đối với Độ an toàn của Sendo.vn chưa cao. Đánh giá của khách hàng đối với yếu tố này thấp hơn hẳn so với 3 yếu tố trước đó, chỉ đạt xấp xỉ từ 1.9 đến hơn 3.5 .

Một số đề xuất đối với yếu tố Độ an toàn như sau: Tăng cường độ bảo mật các thông tin cá nhân và dữ liệu tài chính của khách hàng. Áp dụng các công nghệ bảo mật hiện đại, kỹ thuật mã hoá, ứng dụng tường lửa thế hệ mới, kiểm soát truy cập hệ thống... để chống tin tặc, hacker xâm nhập hệ thống ăn cắp dữ liệu cá nhân, thông tin tài khoản khách hàng. Thường xuyên kiểm nghiệm độ an toàn của hệ thống bằng các phương pháp đánh giá rủi ro và tấn công trắc nghiệm. 
Đảm bảo các giao dịch luôn được thực hiện một các chính xác, đặc biệt là các khoản thanh toán trực tuyến. Nếu giao dịch không thành công, việc hoàn tiền cần được diễn ra nhanh nhất có thể, nếu không sẽ làm cho khách hàng cảm thấy việc thực hiện giao dịch trên trang web là không an toàn và sẽ không muốn quay lại sử dụng dịch vụ trực tuyến nữa. Muốn làm được điều này, hệ thống Senpay cần được hoạt động tốt hơn và tự động hoá hơn, thay vì phải làm tay lọc từng đơn hàng một.

Chính sách bảo mật, bảo vệ thông tin cá nhân và thông tin giao dịch vủa Sendo.vn phải được thông báo rõ ràng, nêu cụ thể quyền hạn và giới hạn trách nhiệm của Sendo.vn liên quan đến vấn đề bảo mật. Sendo.vn cần đảm bảo tất cả khách hàng thực hiện giao dịch đều đọc và hiểu rõ chính sách bảo mật của Sendo.vn. Cần tạo điều kiện cho khách hàng giao dịch mà không cần phải đăng nhập hay đăng ký tài khoản. Một số khách hàng hài lòng với phương pháp này vì nó ít phải cung cấp thông tin cá nhân nhất, tuy nhiên phương pháp này cũng có nhiều hạn chế.

Cần thường xuyên nhắc nhở, kiểm tra đạo đức nghề nghiệp của nhân viên để đảm bảo không để lộ thông tin khách hàng. Thường xuyên giữ mối quan hệ với khách hàng cũng là một biện pháp tăng cường kiểm tra chéo, phát hiện dấu hiệu mất an ninh của hệ thống để có biện pháp kịp thời. Lập hệ thống gửi thông báo trên website và cả email đến khách hàng xác thực giao dịch và tình trạng đơn hàng, tình trạng thanh toán để khách hàng yên tâm.

Cần tiếp tục duy trì, nâng cao uy tín và xây dựng hình ảnh, thương hiệu của một trang thương mại điện tử hàng đầu tại Việt Nam hiện nay. Công việc này đòi hỏi một sự đầu tư rất lớn về nguồn lực tài chính, con người và sự đầu tư về thời gian. Tuy nhiên, đổi lại đó là sự tín nhiệm của khách hàng và an tâm khi sử dụng dịch vụ trực tuyến do Sendo.vn cung cấp.

\section{Về các nhân tố Nhân khẩu học}

Theo kết quả nghiên cứu, có sự khác biệt đối với Sự thoả mãn mua sắm tại Sendo.vn Một số đề xuất cho các nhân tố Nhân khẩu học: Chú trọng phát triển ứng dụng Sendo.vn mạnh và mượt hơn, đáp ứng đúng $x u$ hướng của thị trường và khách hàng trẻ thích sử dụng di động. Tiếp tục duy trì điểm mạnh của Sendo.vn đó là nhóm sản phẩm thuộc phân khúc giá thấp. Tuy nhiên, một số ngành hàng trên trang web hiện nay vẫn chưa có các thuộc tính giúp lọc được các sản phẩm có giá thấp ví dụ như "dưới 1 triệu”, "từ 1 - 2 triệu" chẳng hạn,... như vậy sẽ giúp ích rất nhiều cho khách hàng trong việc tìm kiếm sản phẩm phù hợp với thu nhập.

Đầu tư thực hiện các chương trình khuyến mãi cho các khách hàng nữ từ $18-24$ vì đây là tập khách hàng lớn nhất ở Sendo.vn hiện tại, dễ dàng đạt thành công cũng như là gia tăng được sự thoả mãn cho các khách hàng cũ. Thành lập phòng kiểm soát chất lượng để loại bỏ hàng giả, hàng nhái, hàng kém chất lượng, đặc biệt là các sản phẩm có giá trị cao, nhằm gia tăng sự tin tưởng của các khách hàng có mức thu nhập từ 10 triệu trở lên.

Thực hiện các chương trình khuyến mãi trong nội bộ, tăng cường trải nghiệm dịch vụ mua sắm tại Sendo.vn, tận dụng sức mạnh truyền miệng để ngày càng có nhiều khách hàng biết đến hơn. Kết hợp các ngân hàng để thực hiện các chương trình khuyến mãi kèm theo, đáp ứng nhu cầu mua sắm của khách hàng có thu nhập vừa và đủ. Lựa chọn các kênh quảng cáo, truyền thông phù hợp với khách hàng mục tiêu từ $18-24$ tuổi như các kênh OTT Chat, mạng xã hội,...

\section{NHỬNG HẠN CHẾ CỦA NGHIÊN CÚU VÀ HƯỚNG NGHIÊN CÚU TIÊP THEO}

Nghiên cứu còn một số hạn chế như sau: (1) Nghiên cứu chỉ thực hiện cho khách hàng đã mua sắm trực tuyến tại Sendo.vn nên tính đại diện không cao, khó mang tính tổng quát để áp dụng cho các trang thương mại điện tử khác, (2) 
Chỉ nghiên cứu những khách hàng đã sử dụng dịch vụ trực tuyến của Sendo.vn, vì thế sẽ có hạn chế trong việc đưa ra các giải pháp nâng cao chất lượng dịch vụ trực truyến khi chưa có sự so sánh với dịch vụ được cung cấp bởi các trang thương mại điện tử khác, (3) Cách chọn mẫu nghiên cứu theo phương pháp thuận tiện, vì vậy tính đại diện sẽ không cao, (4) Còn có nhiều yếu tố khác ảnh hưởng đến thoả mãn chất lượng dịch vụ tại Sendo.vn mà nghiên cứu này chưa đề cập đến. Đó cũng chính là gợi ý cho những nghiên cứu tiếp theo.

\section{TÀI LIỆU THAM KHẢO}

1. Bachelet, D. (1995). Measuring Satisfaction; or the chain, the tree and the nest. In R. Brookes (Ed.), Customer Satisfaction Research, Amsterdam: Esomar.

2. Bùi Thanh Tráng (2014), Nhận thức rủi ro tác động đến ý định mua sắm trục tuyến của khách hàng, Tạp chí phát triển kinh tế (278), 26 - 38.

3. Cronin J.J. \& Taylor S.A. (1994). SERVPERF versus SERVQUAL: Reconciling PerformanceBased and Perceptions-Minus-Expectations Measurement of Service Quality. Journal of Marketing, 58(January), 125-131.

4. Gronroos, C. (2000). Service Management and Marketing: a Customer Relationship Management Approach ( $2^{\text {nd }}$ ed). Chichester, UK: John Wiley \& Sons, Ltd.

5. Kotler, P. \& Armstrong, G. (2004). Principles of Marketing, 2004, Pearson/Prentice Hall.

6. Lehtinen, J.R. \& Lehtinen, U. (1982). Service quality: a study of quality dimensions. Unpublished Working Paper, Service Management Institute, Helsinki.

7. Oliver, R. L (1993). Cognitive, Affective, and Attribute Bases of the Satisfaction Response. Journal of ConsumerResearch, 20(3), 418-430.

8. Oliver, R. L. (1997). Satisfaction A Behavioral Perspective of the Consumer. New York: McGraw-Hill.

9. Parasuraman, A., \& Berry, L. L., Zeithaml, V. A. (1985). A conceptual model of service quality and its implications for future research. Journal of Marketing, 49, 41-50.

10. Parasuraman, A., Zeithaml V. A., \& Malhotra, A. (2005). E-S QUAL: Multiple-Item Scale For Assessing Electronic Service Quality. Journal of Service Research, 7(3), 213 - 234.

11. Parasuraman, A., Zeithaml, A. V., \& Berry, L. L. (1988). SERVQUALl: A Multiple-Item Scale For Measuring Consumer Perceptions of Service Quality. Journal of Retailing 64(1), 12 - 40.

12. Santos, J. (2003). E-service quality: a model of virtual service quality dimensions. Management Service Quality, 13(3), 233 - 246.

13. Spreng, R.A., \& Mackoy, R.D. (1996). An empirical examination of a model of perceived service quality and satisfaction. Journal of Retailing, 72, 201-214.

14. Wolfinbarger, M., \& Gilly, M. C. (2003). EtailQ: Dimensionalizing, Measuring and Predicting etail Quality. Journal of Retailing, 79(3), 183 - 198.

15. Zeithaml, V., \& Bitner, M. (2003). Services Marketing. New York, NY: Mc Graw-Hill. 